Prof. C. Chilton enumerates the Amphipoda and Isopoda, and of the first-mentioned order eight species are now known to occur. Of the Isopoda eight species likewise are listed, and of these the most notable is Paravireia typicus gen. et sp. nov. This crustacean belongs to the family Sphæromidre and is a fresh-water form. A remarkable fact concerning this type is that it is allied to the genus Vireia which occurs in underground waters in Europe. The spiders are discussed by M. Lucien Berland, who adds two species new to science, making a total of twenty species now recorded from the islands. The affinities of these spiders, he remarks, are entirely with New Zealand-they have no affinity with S. American forms.

\section{Inheritance of Induced Melanism in Lepidoptera.}

I W. H. HARRISON and F. C. Garrett (Proc. Roy. J. Soc., B, vol. 99, p. 24I, Feb. I926) record the results of some eight years' observation and experiment upon the inheritance of melanism induced in Geometrid moths by the addition of lead and manganese to their diet. The increase of melanism among various Lepidopteran species in industrial districts of England and the Continent has excited the attention of the field naturalist and the general biologist for some time, and in I920 Dr. Harrison made the suggestion (Journ. Genetics, 9, 3, p. I95) that the increase in melanism was due to the modification of the body pigments through various salts deposited on the food plants in areas where the atmosphere is charged with smoke.

This suggestion was submitted to experimental verification, and the result is the most unequivocal proof which has yet been obtained of the inheritance of an experimentally induced modification. Individuals of three species, Selenia bilunaria and Tephrosia bistortata and crepuscularia were used. Normal (non-melanic) individuals were obtained from rural districts of the south of England. Some of them were kept as controls on normal food and, though bred for several generations, showed no melanism. Others were submitted to experimental conditions, the $S$. bilunaria individuals being fed on hawthorn treated with lead nitrate and manganese sulphate, the $T$. bistortata being fed on roadside hawthorn gathered in an industrial district (north Durham) where there is an abundance of wild melanic forms. In both cases melanism appeared in the experimental animals, and was inherited in S. bilunaria and $T$. bistortata as a Mendelian recessive, in $T$. crepuscularia (p. 245) as a dominant.

The technical procedure in these experiments seems to leave no room for criticism; though we would like to hear the author's views as to why in certain cases (pp. 245 and 246 ) the number of animals which are experimentally modified is so low $(22: \mathrm{I}, 26: \mathrm{I}$, and $29: 2)$. Further experiments are contemplated with the view of discovering the active agent which produces the colour change, the authors expressing a doubt as to whether it may not be the acid radical of the compounds employed instead of the metal.

\section{A Journal of Marine Investigations.}

THE recent issue of the first number of the Journal $d u$ Conseil marks the start of a new and welcomed venture in publication by the Conseil permanent international pour l'exploration de la Mer. British readers in particular will find pleasure in the fact that Dr. E. S. Russell, the Director of Scientific Fishery
Investigations of the Ministry of Agriculture and Fisheries, has undertaken the difficult task of editing this important work. The Journal will, it is hoped appear quarterly, each number containing a general article on some aspect of the Council's work, one or two short scientific articles such as have hitherto been published in the Publications de Circonstance (which series will now be discontinued), notes on current work, reviews, and a current bibliography. The first number is a noteworthy commencement. The general article is written in English by Prof. Johan Hjort on "Fluctuations in the Year Classes of Important Food Fishes," and a résumé in French follows. The scientific article, also in English, on "The Relation between Cod-end Mesh and Size of Fish Caught" describes some preliminary experiments with the Trouser trawl, and should be of especial interest to the practical men of the trawling industry.

Thirteen papers in all are reviewed, the name of the reviewer in each case being given. It will probably be noticed that twelve of the thirteen papers reviewed were published in English, and of these nine were written by British investigators. Moreover, only two of the reviews were prepared by Continental writers. Many readers would be greatly assisted in their work if it could be found practical to include reviews of papers appearing in languages which are generally unfamiliar. If, also, the list of reviewers could be made to include representatives of the several nations interested in the work of the Council, a great store of experience and thought would become available to the readers of the Journal.

Part i. of a selected bibliography of marine bionomics and fishery investigation, compiled by. Dr. E. J. Allen, will be generally welcomed. Part ii. is to appear in the second number of the Journal, and it is proposed to re-issue the bibliography, when complete, as a separate publication. Starting with No. 3 of the Journal the current bibliography will be issued to subscribers in the form of sheets printed on one side only, as well as being printed in the Journal in the ordinary way.

\section{University and Educational Intelligence.}

CAMBridge.-The effects of the general strike were very marked. The Council of the Senate naturally made no recommendation as to the course which persons in statu pupillari should adopt. A tutors' committee dealt with instructions to those who wished to volunteer for service in various capacities. unfortunately, this committee gave instructions before an adequate organisation capable of dealing with masses of volunteers had been created. The result was semi-chaos, reminiscent of the eariy autumn of I9I 4 .

The University ceased to give formal instructions between May 9 and I6. All triposes have been postponed, some for a week and some for a fortnight. As a result of this scheme the carefully devised plan on which the examinations are usually arranged in space and time has been dislocated, and the Board responsible for the organisation is faced with the prospect of providing for some 2000 candidates for university examinations on certain days ( 1500 is usually regarded as the maximum).

EDINBURGH.-At the meeting of the University Court on Monday, May I7, an intimation was received from Prof. B. P. Watson, professor of midwifery and diseases of women, of his intention to resign upon his appointment as professor of obstetrics and gynæcology in Columbia University, New York. The Court received his intimation with regret.

NO. $295 \mathrm{I}$, VOL. I I 7$]$ 